\title{
TOXICITY OF FENVALERATE ON LARVAE OF THE SUSCEPTIBLE AND RESISTANT STRAINS OF TRIBOLIUM CASTANEUM (HERBST)
}

\author{
Saiful Islam Faruki*, Rogena Yeasmin and Dipali Rani Das \\ Department of Zoology, University of Rajshahi, Rajshahi 6205, Bangladesh \\ *Corresponding author (email: faruki64@yahoo.com)
}

\begin{abstract}
Five-day old larvae of the susceptible (FSS-II) and organophosphorus-resistant (PH-I) strains of the red flour beetle Tribolium castaneum were exposed under laboratory conditions to food treated with $100,250,500$ and 1000 ppm of a synthetic pyrethroid Fenvalerate up to adult emergence. The larval mortality was assessed at 1-, 3-, 7- and 15-days post-exposure, and up to pupation. PH-I was found less susceptible to Fenvalerate than FSS-II which required 1.2 to 3.1 fold more insecticide to induce $50 \%$ mortality. The pyrethroid treatments significantly increased the larval and pupal periods $(\mathrm{P}<0.05)$ in both the strains and the formation of pupal and adult progenies was adversely affected $(\mathrm{P}<0 \cdot 001)$.
\end{abstract}

Key words: Fenvalerate, Tribolium castaneum, mortality, developmental periods, progeny recovery.

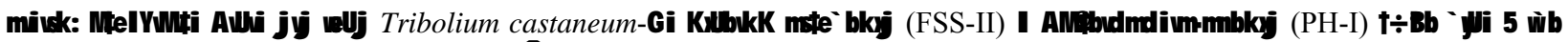

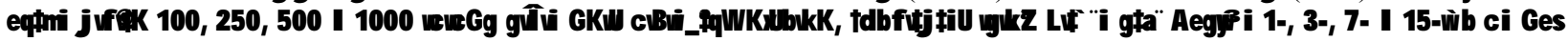

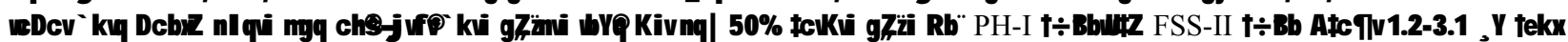

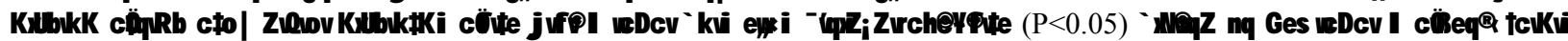
A wef $\mathrm{Z}$ richorfoute $(\mathrm{P}<0.001) \mathrm{K} \neq \mathrm{g}$ hral

\section{Introduction}

Grains in storage are damaged by the activities of several species of insect pests, the commonest being the beetles and moths, leading to loss in qualities such as weight, quality, texture, taste, colour, nutritional and commercial values and seed viability. Majority of these storage insect pests are coleopterans and the most damaging species belong to the genera Sitophilus and Tribolium (Marsans 1987; Pinto et al. 1997). The red flour beetle Tribolium castaneum (Herbst) (Coleoptera: Tenebrionidae) is an ubiquitous pest of economic importance which damages the products at both larval and adult stages. Due to severe infestations the flour may have a characteristic pungent odour and pinkishbrown in colour by the secretion of quinones (Markarian et al. 1978), affecting the viscous and elastic properties of the flour and creating a taint which may cause gastric disturbances if used as food (Payne 1925; Engelhardt et al. 1965; Mondal 1992). To avoid these, T. castaneum has usually been controlled primarily by the use of chemical insecticides (O’Donnell 1980; Evans 1985; Binns 1986). The development of resistance among populations of this species against organochlorides, organophosphates and certain fumigants has been reported throughout the world (Dyte and Blackman 1970; Zettler and Jones 1977; Zettler 1982; Saleem and Shakoori 1990, Zettler and Cuperus 1990). The resistance and contamination problems have, therefore, brought about interest in the use of a safer insecticide, like the synthetic pyrethriods due to their significant insecticidal properties (Elliott and Janes 1973; Elliott et al. 1978). The use of pyrethroids became worldwide because of their good knock down and lethal activity to insects, low mammalian toxicity, photostability, high degradability and effective at minimum dose (Barlow et al. 1971; Hadaway 1972). Because of insecticidal and lethal activity, many researchers have done a plenty of works on synthetic pyrethroids for determination of lethal dose and enzymatic activities against a number of insects (Tabassum et al. 1998; Mujeeb and Shakoori 2007; Yousuf et al. 2008). The purpose of this study was to evaluate the toxic effects of a synthetic pyrethroid, fenvalerate against a susceptible (FSS-II) and an organophosphorus-resistant (PH-I) strains of $T$. castaneum for successful control of this noxcious stored products species.

\section{Materials and Methods}

Mass rearing of the beetles: FSS-II and PH-I strains of the beetles were cultured on a whole meal wheat flour and yeast medium at the Insect Research Laboratory, Department of Zoology, Rajshahi University. The culture was maintained in glass jars $(25 \mathrm{~cm} \times 11 \mathrm{~cm})$ at $30 \pm 1^{\circ} \mathrm{C}$ in an incubator without any light and humidity control. The flour was sterilized at $60^{\circ} \mathrm{C}$ for $3 \mathrm{~h}$. About half of each jar was filled with flour-yeast medium in which 300 unsexed beetles of each strain were introduced separately. The mouths of the jars were 
covered with coarse cloth, tied with rubber bands, to avoid escape of the beetles. The medium was sieved on the following day to collect eggs that were kept in Petri dishes for hatching. Newly-hatched larvae were cultured on the same food medium to obtain 5-day old larvae for the experiment.

Insecticide used: Technical grade of the synthetic pyrethroid, fenvalerate $(98 \%)$ used in the present investigation was supplied by the Department of Agricultural and Environmental Sciences, University of Newcastle upon Tyne, UK, as a liquid. This widely used pyrethroid is a clear yellow, viscous liquid having broad-spectrum against insects and chemically it is cyano (3-phenoxyphenyl) methyl-4-chloro- $\alpha$-(1-methylethyl) benzeneacetate.

Bioassays: For determination of larval dose-mortality, developmental periods, and progeny (pupal and adult) recoveries, four different concentrations of the chemical viz. 100, 250, 500 and 1000ppm were prepared by mixing the insecticide with requisite amounts of flour. Acetone was used as the solvent which was allowed to evaporate for $3 \mathrm{~h}$ prior to introduction of larvae in the food medium. Twenty five 5-day old larvae of FSS-II and PH-I strains of $T$. castaneum were introduced separately into each Petri dish (9-cm diameter) provided with fenvalerate treated food up to adult emergence. The same number of insects was exposed to only acetone treated food maintained as controls. Three replicates were used for each treatment and control. Petri dishes were kept in an incubator at $30 \pm 1^{\circ} \mathrm{C}$ without any light and humidity control. Dead larvae were counted at 1-, 3-, 7- and 15-day post exposure, and up to pupation. The percentage mortalities were corrected by the Abbott's (1925) formula as follows:

Corrected $(\%)$ mortality $=$

Test mortality (\%) - Control mortality $(\%) \times 100$ 100 - Control mortality (\%)

The corrected mortalities were then subjected to Probit analysis following the methods by Busvine (1971), the regression lines were drawn and the $\mathrm{LC}_{50}$ values were determined. Larvae were regularly checked for pupation while noting the larval periods. After pupation, insects were collected and kept in Petri dishes for adult eclosion. The number of adults that emerged from different concentrations was recorded for computing the pupal period. The numbers of pupal and adult progenies were also noted.
The percentages of reduction in pupal and adult progenies were calculated using the formula, PR (percent reduction) $=\left(C_{r}-T_{r}\right) / C_{r} \times 100$, where $C_{r}$ is the mean $(\%)$ recovery in controls and $\mathrm{T}_{\mathrm{r}}$ is the mean (\%) recovery in treatment groups. Data on all the parameters finally were subjected to analysis of variance and the differences between the means were determined by the Tukey's multiple comparison procedure.

\section{Results and Discussion}

Fenvalerate was effective against both the strains of $T$. castaneum. The results are summerised in the following paragraphs.

Concentration-mortality response: $\mathrm{LC}_{50}$ values for 5day old larvae of $T$. castaneum exposed to various concentrations of fenvalerate at different exposure periods are shown in Table 1. PH-I strain showed more tolerance, requiring 1.2-3.0 fold more chemical to kill $50 \%$ larvae than that in FSS-II. Regression lines indicated positive relationships between the concentrations and mortalities, i.e. the mortalities increased with increasing concentrations (Figs. 1 and 2). The present findings therefore showed that fenvalerate was toxic to both strains of $T$. castaneum, although a complete control would require higher concentrations than those used in the present study.

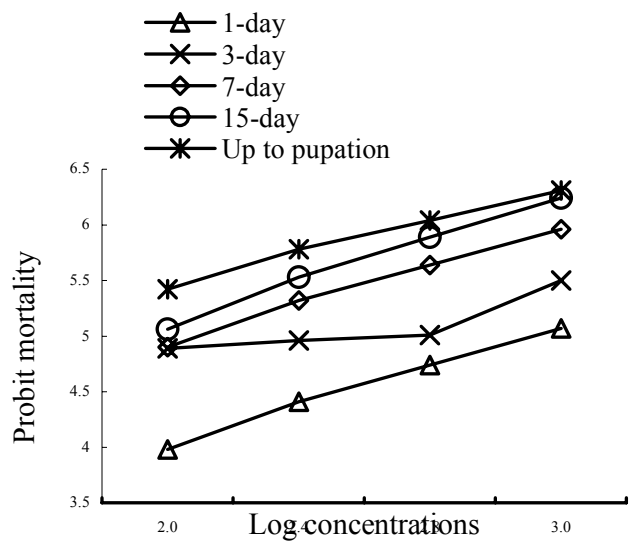

Fig. 1. Probit mortality regression line for T. castaneum larvae of FSS-II strain when exposed to fenvaleratetreated food for different durations. 


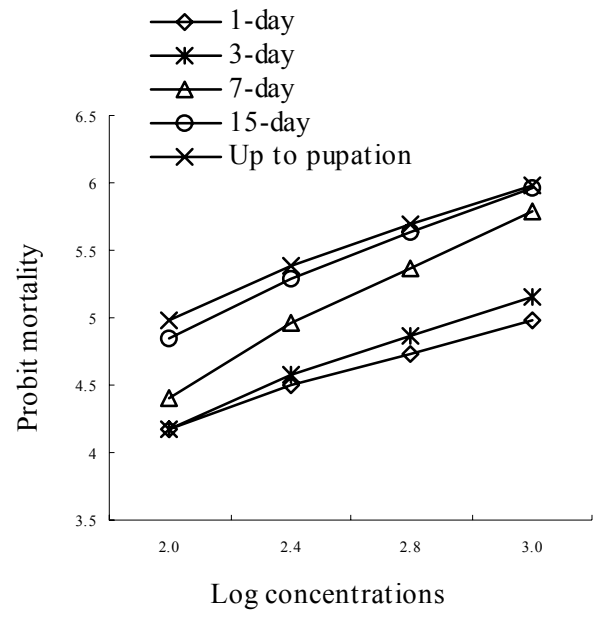

Fig. 2. Probit mortality regression line for $T$. castaneum larvae of PH-I strain when exposed to fenvaleratetreated food for different durations.
Effects of fenvalerate on progeny production: The pyrethroid caused significant reduction in pupal $\left(\mathrm{F}_{4 / 4}=\right.$ 135.81, $\mathrm{P}<0.001)$ and adult $\left(\mathrm{F}_{4 / 4}=173.17, \mathrm{P}<0.001\right)$ progenies in FSS-II and PH-I strains of T. castaneum (Table 2). The larvae that survived and succeeded pupation leading to adult emergence decreased with increasing concentrations. The adult progeny production in FSS-II strain was completely suppressed at 1000ppm while it was 97\% in PH-I strain as compared to the controls.

Effects of fenvalerate on developmental periods: The larval and pupal periods were gradually increased from lower to higher concentrations of the insecticide (Table 3). Analysis of variance showed that fenvalerate significantly lengthened the larval $\left(\mathrm{F}_{3 / 3}=26.28, \mathrm{P}<0.05\right)$ and pupal $\left(\mathrm{F}_{3 / 3}=19.99, \mathrm{P}<0.05\right)$ periods in $T$. castaneum strains.

Table 1. Lethal concentrations of fenvalerate against 5-day old larvae of $T$. castaneum at different exposure periods.

\begin{tabular}{c|c|c|c|c}
\hline Exposure periods (days) & Strains & LD $_{50}(\mathrm{ppm})$ & Regression equation & $\chi^{2}$-values $(\mathrm{df})$ \\
\hline 1 & FSS-II & 872.06 & $1.79+1.09 \mathrm{x}$ & $0.62(2)$ \\
& PH-I & 1057.63 & $2.56+0.81 \mathrm{x}$ & $0.56(2)$ \\
3 & FSS-II & 462.56 & $2.30+1.07 \mathrm{x}$ & $2.50(2)$ \\
& PH-I & 682.66 & $2.21+0.98 \mathrm{x}$ & $1.40(2)$ \\
7 & FSS-II & 124.26 & $2.78+1.06 \mathrm{x}$ & $0.76(2)$ \\
& PH-I & 238.63 & $1.65+1.38 \mathrm{x}$ & $0.18(2)$ \\
& FSS-II & 88.55 & $2.70+1.18 \mathrm{x}$ & $2.89(2)$ \\
& PH-I & 140.46 & $2.55+1.14 \mathrm{x}$ & $1.97(2)$ \\
Up to pupation & FSS-II & 33.47 & $3.65+0.98 \mathrm{x}$ & $0.98(2)$ \\
& PH-I & 105.19 & $2.95+1.02 \mathrm{x}$ & $1.27(2)$ \\
\hline
\end{tabular}

Table 2. Effect of Fenvalerate on the production of pupal and adult progenies from T. castaneum larvae.

\begin{tabular}{|c|c|c|c|c|c|c|c|}
\hline Strains & $\begin{array}{c}\text { Concentrations } \\
(\mathrm{ppm})\end{array}$ & $\begin{array}{c}\text { Pupal } \\
\text { recovery }(\%)\end{array}$ & $* \mathrm{PR}$ & F-values & $\begin{array}{c}\text { Pupal } \\
\text { recovery } \\
(\%)\end{array}$ & $* \mathrm{PR}$ & F-values \\
\hline \multirow{5}{*}{ FSS-II } & 0 (Control) & $85.00^{\mathrm{a}}$ & - & \multirow{10}{*}{$\begin{array}{l}\text { (a) } 135.81^{* * *} \\
\text { (b) } 3.91^{\mathrm{ns}}\end{array}$} & $73.33^{\mathrm{a}}$ & - & \multirow{10}{*}{$\begin{array}{l}\text { a) } 173.17^{* * *} \\
\text { (b) } 4.64^{\mathrm{ns}}\end{array}$} \\
\hline & 100 & $25.00^{\mathrm{c}}$ & 70.59 & & $16.67^{\mathrm{c}}$ & 77.27 & \\
\hline & 250 & $10.00^{\mathrm{e}}$ & 88.24 & & $6.67^{\mathrm{d}}$ & 90.90 & \\
\hline & 500 & $6.67^{\mathrm{f}}$ & 92.15 & & $3.33^{\mathrm{e}}$ & 95.46 & \\
\hline & 1000 & $1.67^{\mathrm{g}}$ & 98.04 & & 00 & 100 & \\
\hline \multirow{5}{*}{ PH-I } & 0 (Control) & $83.33^{\mathrm{a}}$ & - & & $73.33^{\mathrm{a}}$ & - & \\
\hline & 100 & $35.00^{\mathrm{b}}$ & 58.00 & & $25.00^{\mathrm{b}}$ & 65.91 & \\
\hline & 250 & $21.67^{\mathrm{d}}$ & 74.00 & & $16.67^{\mathrm{c}}$ & 77.27 & \\
\hline & 500 & $10.00^{\mathrm{e}}$ & 88.00 & & $5.00^{\mathrm{d}}$ & 93.18 & \\
\hline & 1000 & $3.33^{\mathrm{g}}$ & 96.00 & & $1.67^{\mathrm{f}}$ & 97.72 & \\
\hline
\end{tabular}

Note: $(\mathrm{a})=$ between concentrations, $(\mathrm{b})=$ between strains; $* * * \mathrm{P}<0.001, \mathrm{~ns}=$ not significant; $* \mathrm{PR}=$ percent reduction over control. Means followed by dissimilar letters within each column are significantly different by Tukey's multiple comparison tests $(\mathrm{P}<0.05)$. 
Table 3. Developmental periods (days) of fenvalerate treated T. castaneum larvae.

\begin{tabular}{|c|c|c|c|c|c|}
\hline Strains & $\begin{array}{c}\text { Concentrations } \\
\text { (ppm) }\end{array}$ & $\begin{array}{l}\text { Larval period } \\
\text { (days) }\end{array}$ & F-values & $\begin{array}{l}\text { Pupal period } \\
\text { (days) }\end{array}$ & F-values \\
\hline \multirow{5}{*}{ FSS-II } & 0 (Control) & $22.47 \pm 1.45^{\mathrm{a}}$ & & $5.45 \pm 0.50^{\mathrm{a}}$ & \multirow{10}{*}{$\begin{array}{l}\text { (a) } 19.99^{*} \\
\text { (b) } 0.02^{\mathrm{ns}}\end{array}$} \\
\hline & 100 & $32.60 \pm 1.18^{\mathrm{bc}}$ & & $9.50 \pm 1.28^{\mathrm{bc}}$ & \\
\hline & 250 & $34.17 \pm 1.17^{b}$ & & $9.25 \pm 1.09^{b c}$ & \\
\hline & 500 & $37.75 \pm 1.71^{\mathrm{d}}$ & & $10.00 \pm 1.00^{\mathrm{cd}}$ & \\
\hline & 1000 & NA & (a) $26.28^{*}$ & NA & \\
\hline \multirow{5}{*}{ PH-I } & 0 (Control) & $22.64 \pm 2.76^{\mathrm{a}}$ & (b) $6.87^{\mathrm{ns}}$ & $5.61 \pm 0.49^{\mathrm{a}}$ & \\
\hline & 100 & $29.86 \pm 1.39^{c}$ & & $8.07 \pm 0.77^{\mathrm{b}}$ & \\
\hline & 250 & $29.47 \pm 1.45^{\mathrm{c}}$ & & $9.60 \pm 0.66^{\mathrm{cd}}$ & \\
\hline & 500 & $33.67 \pm 1.87^{b}$ & & $10.67 \pm 0.47^{\mathrm{d}}$ & \\
\hline & 1000 & NA & & NA & \\
\hline
\end{tabular}

Note: (a) = between concentrations, (b) $=$ between strains; ${ }^{*} \mathrm{P}<0.05$, ns $=$ not significant. Means followed by dissimilar letters within each column are significantly different by Tukey's multiple comparison tests $(\mathrm{P}<0.05)$; NA $=$ not applicable.

Fenvalerate used in the present study induced higher mortalities in both FSS-II and PH-I strains of $T$. castaneum. Yadav (1987) reported that the synthetic pyrethroids, deltamethrin and cypermethrin were most toxic to 13 stored product insects including $T$. castaneum. Bry et al. (1980) recorded 100\% mortality for 1st instar larvae of Attagenus megatoma using permethrin. Similar effects of deltamethrin, cypermethrin, permethrin and fenvalerate have been reported for Callosobruchus maculatus and C. chinensis (Rahman and Yadav, 1987). However, O’Brien (1967) commented that pyrethroids may affect the sodium and potassium permeability and nitrogen metabolism in insect cells. In addition, pyrethroids may also affect the peripheral and central nervous systems causing rapid paralysis and eventual death (O’Brien, 1967).

Faruki and Khan (2004a, b) observed significantly higher reductions in pupation and adult emergence when larvae of Cadra cautella were reared on cypermethrin-treated groundnuts. Reductions in emergence of $C$. maculatus and $C$. chinensis were recorded from treatments of various developmental stages with different pyrethroids (Rahman and Yadav 1987). Significantly reduced pupation and adult emergence in the Indian mealmoth, Plodia interpunctella were also noted by Arthur (1997, 1999) when $5^{\text {th }}$ instar larvae were exposed to deltamethrin and cyfluthrin residues for short periods. Shour and Crowder (1980) recorded that in larvae of Chrysoperla carnea, topically treated with permethrin or fenvalerate, the rate of pupation was significantly reduced. Tabassum et al. (1998) and Yousuf et al. (2008) working with Alphitobius diaperimus, Sitophilus oryzae and $T$. castaneum reported that pyrethroids were very much effective in reducing their population either by killing or inhibiting progeny that agreed with the present findings. Significantly lengthened developmental periods observed in the present treated insects that corroborate to the findings of Faruki and Khan (2004a, b).

\section{Conclusion}

The present results showed that fenvalerate effectively increased the mortality, lengthened the developmental periods, and reduced the production of pupal and adult progenies in both susceptible and resistant strains of $T$. castaneum which is very much desirable in stored products pest management programmes. It may therefore be concluded that fenvalerate may be used to protect stored product commodities from insect infestations.

Acknowledgements: The authors are grateful to the Department of Agricultural and Environmental Sciences, University of Newcastle upon Tyne, UK, for supplying the technical grade of the insecticide. The authors extend their sincere thanks to the Chairman, Department of Zoology, Rajshahi University, Bangladesh, for providing necessary laboratory facilities.

\section{References}

Abbott WS. 1925. A method for computing the effectiveness of an insecticide. J. Econ. Entomol. 18: 265-267.

Arthur FH. 1997. Residual susceptibility of Plodia interpunctella to deltamethrin dust: Effects of concentration and time of exposure. J. Stored Prod. Res. 33(4): 313-319.

Arthur FH. 1999. Residual susceptibility of fifth instar Plodia interpunctella to cypermethrin wettable powder. J. Stored Prod. Res. 35: 99-105. 
Barlow F, Elliott M, Farnham AW, Hadaway AB, Janes NF, Needham PH and Wickham JC. 1971. Insecticide activity of the pyrethrins and related compounds essential features of insecticide activity in chryseinthemates and related cyclopropane esters. Pestic. Sci. 2: 115-118.

Binns TJ. 1986. The comparative toxicity of malathion, with and without the addition of triphenyl phosphate, to adults and larvae of a susceptible and two resistant strains of Tribolium castaneum (Herbst)(Coleoptera: Tenebrionidae). J. Stored Prod. Res. 22: 97-101.

Bry RE, Boatright RE and Lang JH. 1980. Ovicidal effect of permethrin against the black carpet beetle and the webbing clothes moth. J. Econ. Entomol. 73(3): 449-450.

Busvine JR. 1971. A Critical Review of the Techniques for Testing Insecticides. CAB, England, 345 pp.

Dyte CE and Blackman DG. 1970. The spread of insecticide resistance in Tribolium castaneum (Herbst) (Coleoptera: Tenebrionidae). J. Stored Prod. Res. 6: 255-261.

Elliott M and Janes NF. 1973. Chemistry of the natural insecticides. (ed. JE Casida), pp. 56-100.

Elliott M, Janes NF and Rettor C. 1978. The future of pyrethroids in insect control. Ann. Rev. Entomol. 23: 443-469.

Engelhardt M, Rapoport H and Sokoloff A. 1965. Odorous secretions of normal and mutant Tribolium castaneum. Science 150: 632-633.

Evans NO. 1985. The effectiveness of various insecticides on some resistant beetle pests of stored products from Uganda. J. Stored Prod. Res. 219: 105-109.

Faruki SI and Khan AR. 2004a. Effect of insecticide on the irradiated tropical warehouse moth, Cadra cautella (Walker)(Lepidoptera: Phycitidae). J. bio-sci. 4(5): 681-686.

Faruki SI and Khan AR. 2004b. Combined action of Bacillus thuringiensis ssp. kurstaki and the pyrethroid, Fenom $^{\circledR}$ on Cadra cautella (Walker)(Lepidoptera: Phycitidae). Bangladesh J. Zool. 32(2): 225-233.

Hadaway AB. 1972. Toxicity of insecticide to testse flies. Bull. Wld. Hlth. Org. 46: 353-362.

Markarian H, Florentine GJ and Pratt JJJ. 1978. Quinone production in some species of $T$. castaneum. $J$. Insect Physiol. 2: 785-790.

Marsans G. 1987. Manejo y Conservación de Granos. Hemisferio Sur, Buenos Aires, 266 pp.

Mondal KAMSH. 1992. Quinone secretions of flour beetles, Tribolium: Problems and prospects. Tribolium Inf. Bull. 32: 78-89.

Mujeeb KA and Shakoori AR. 2007. Toxicity of synthetic pyrethroid, Fury, against different developmental stages of three strains of Tribolium castaneum (Herbst). Pakistan J. Zool. 39(6): 361-366.
O’Brien RD. 1967. Insecticides, Action and Metabolism. Academic Press, London, New York.

O'Donnell MJ. 1980. The toxicity of four insecticides to Tribolium confusum Duv. in two sets of conditions of temperature and humidity. J. Stored Prod. Res. 16: 71-74.

Payne N. 1925. Some effects of Tribolium on flour. J. Econ. Entomol. 18: 737-743.

Pinto Jr AR, Furiatti RS, Pereira PVS and Lazzari FA. 1997. Avaliacao de Insecticidas no Controle deSitophilus oryzae (L.)(Coleoptera: Curculionidae), e Rhizopertha dominica (Fab.)(Coleoptera: Bostrichidae) em Arroz Armazenado. Anais Soc. Entomol. Brasil. 26: 285-290.

Rahman MM and Yadav TD. 1987. Efficacy of deltamethrin, cypermethrin, permethrin and fenvalerate dusts against developmental stages of Callosobruchus maculatus Fab. C. chinensis Linn. Indian $J$. Entomol. 49(3): 387-391.

Saleem MA and Shakoori AR. 1990. The toxicity of eight insecticides to sixth instar larvae and adult beetles of T. castaneum (Herbst). Pakistan J. Zool. 22: 207216.

Shour MH and Crowder LA. 1980. Effects of pyrethroid insecticides on the common green lacewing. $J$. Econ. Entomol. 73: 306-309.

Tabassum R, Naqvi SNH, Jahan M, Nurulain SM, Khan MF and Azmi MA. 1998. Determination of toxicities of the fenpropathrin (pyrethroid) and neem formulation (RB-a $+\mathrm{PBO}+\mathrm{TX}-100)$ against Alphitobius diaperinus adults and their effects on transaminases. Tr. J. Zool. 22: 319-322.

Yadav TD. 1987. Toxicity of deltamethrin, cypermethrin, permethrin against thirteen stored product insects. Indian J. Entomol. 49(1): 21-26.

Yousuf MJ, Anjum SI and Khawaja S. 2008. Toxicity determination of some pyrethroids against Tribolium castaneum and Sitophilus oryzae and its effect on transaminases (GOT and GPT). J. Chem. Soc. Pak. 30(5): $770-774$.

Zettler JL. 1982. Insecticide resistance in selected stored product insects infesting peanuts in the southern United States. J. Econ. Entomol. 75: 359-362.

Zettler JL and Jones RD. 1977. Toxicity of seven insecticides to malathion resistant red flour beetle. J. Econ. Entomol. 70: 536-538.

Zettler JL and Cuperus GW. 1990. Pesticide resistance in Tribolium castaneum (Coleoptera: Tenebrionidae) and Rhyzopertha dominica (Coleoptera: Bostrichidae) in wheat. J. Econ. Entomol. 83: 16771681.

Manuscript received on 6 August 2011 and revised on 30 October 2011 